\title{
Clinoidal Meningioma with Cavernous Sinus Invasion
}

\author{
Adriana Azeredo Coutinho Abrao ${ }^{1}$ Carlos Eduardo da Silva ${ }^{1,2}$ \\ ${ }^{1}$ Department of Neurosurgery and Skull Base Surgery, Hospital \\ Ernesto Dornelles, Porto Alegre, Rio Grande do Sul, Brazil \\ 2 Federal University of Health Sciences of Porto Alegre- UFCSPA, Porto \\ Alegre, Rio Grande do Sul, Brazil \\ Address for correspondence Carlos Eduardo da Silva, MD, PhD, \\ Department of Neurosurgery and Skull Base Surgery, Hospital Ernesto \\ Dornelles, Porto Alegre, RS 90160-092, Brazil \\ (e-mail: dasilvacebr@yahoo.com.br).
}

J Neurol Surg B Skull Base 2022;83(suppl S3):e613-e614.

\begin{abstract}
Keywords

- meningioma

- anterior clinoid

- cavernous sinus

- sphenoid wing

We present a-49-year old female presenting headache and progressive right eye visual loss in the last 6 months. Magnetic resonance imaging showed a large clinoidal meningioma on the right side, invading the superior, lateral and medial aspects of the cavernous sinus, the optic canal, and the clinoidal segment of the internal carotid artery (ICA).

A cranio-orbital approach was performed. The anterior clinoid process was removed extradurally to achieve devascularization of the anterior clinoidal meningioma, followed by the peeling of the middle fossa to decompress V2 and open the superior orbital fissure. We open the dura in a standard fronto-temporal flap to access the lower portion of the skull base allowing retractorless dissection. We complete the removal of the anterior clinoid process and optic strut through an intradural approach. It allows safer dissection of the clinoidal segment of the ICA and avoids its injury by adherent and hard consistency tumor.

Intraoperative neurophysiological monitoring, sharp dissection, and avoiding the use of bipolar coagulation when dissecting the cavernous sinus are essential to minimize the risk of cranial nerve injury. We also like to point that cranial nerve deficit caused by surgical manipulation without primary lesion of the nerve can be recovered postoperatively.

The link to the video can be found at: https://youtu.be/ozUCsnUGxyM.
\end{abstract}

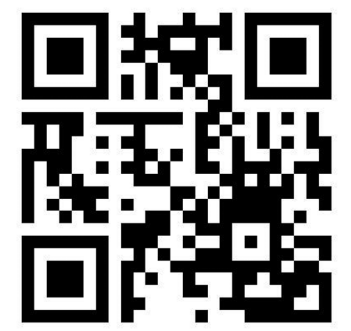

received

March 27, 2020

accepted

October 31, 2020

published online

May 17, 2021 www.thieme.com/skullbasevideos

www.thieme.com/jnlsbvideos

DOI https://doi.org/

10.1055/s-0041-1727109.

ISSN 2193-6331.

\footnotetext{
(C) 2021. The Author(s).

This is an open access article published by Thieme under the terms of the Creative Commons Attribution-NonDerivative-NonCommercial-License, permitting copying and reproduction so long as the original work is given appropriate credit. Contents may not be used for commercial purposes, or adapted, remixed, transformed or built upon. (https://creativecommons.org/ licenses/by-nc-nd/4.0/) Georg Thieme Verlag KG, Rüdigerstraße 14, 70469 Stuttgart, Germany
} 


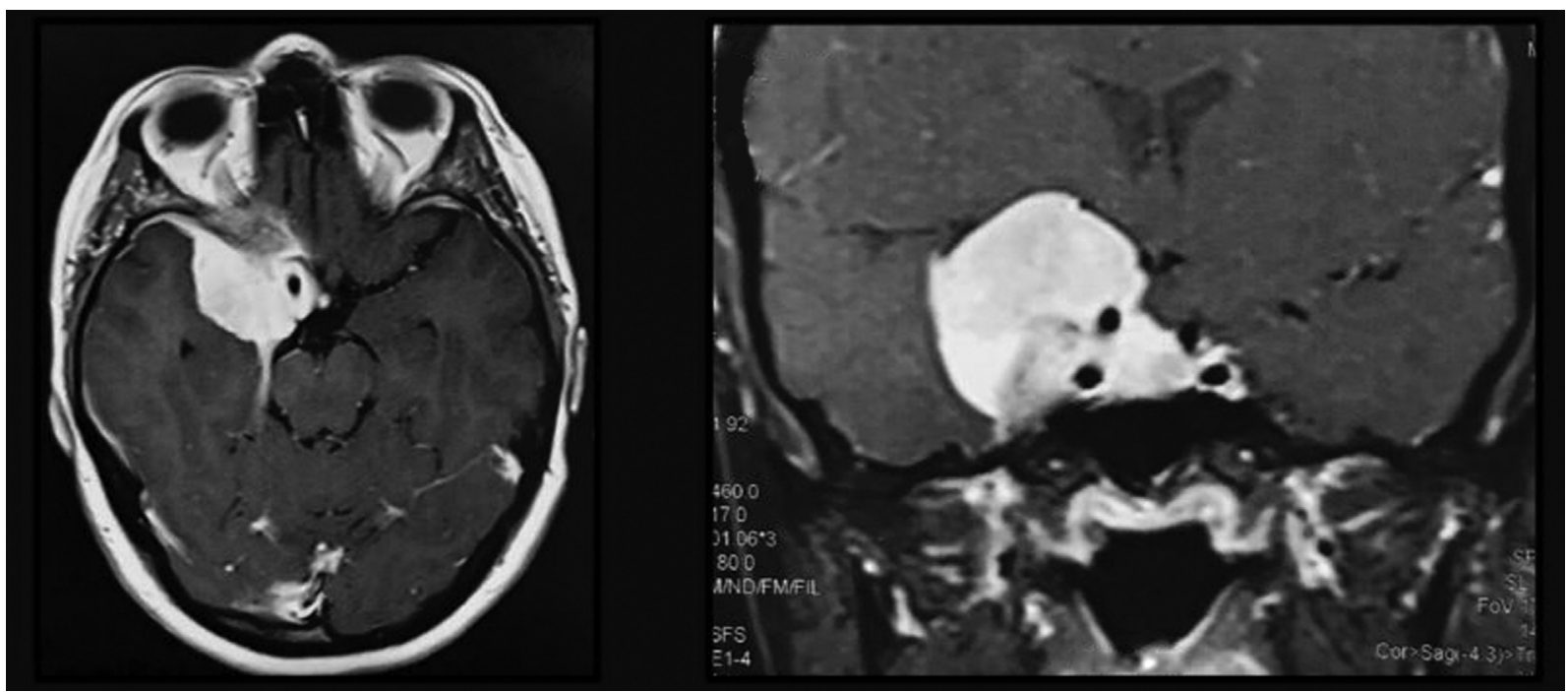

Fig. 1 Axial and coronal magnetic resonance imaging show a large clinoidal meningioma on the right side, invading the superior, lateral and medial portion of the cavernous sinus, the optic canal and circumferential involvement of the internal carotid artery. It extends also to the temporal floor.

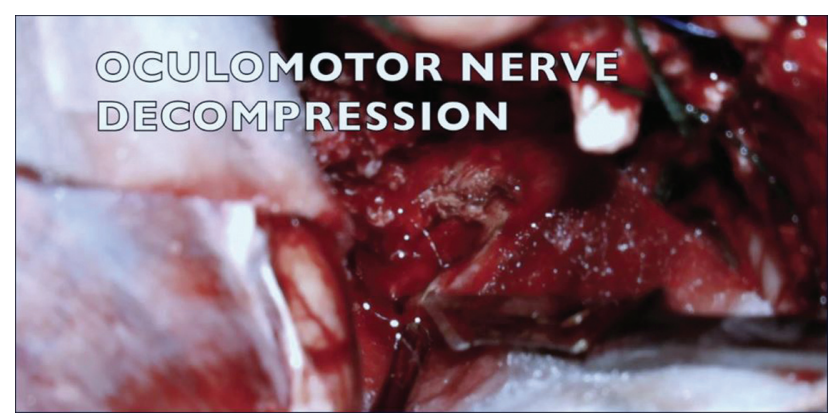

Fig. 2 Intraoperative image demonstrating sharp dissection of the oculomotor triangle to release the third nerve.

\section{Note}

The manuscript has not been previously published or submitted elsewhere for review.

\section{Conflict of Interest}

None declared. 